\title{
OJS OPEN

\section{APLICAÇÃO DIDÁTICA DO GOOGLE EARTH PRO: SEMIOLOGIA GRÁFICA, VARIÁVEIS VISUAIS E MODOS DE IMPLANTAÇÃO}

\author{
Luciana Belso Pinheiro ${ }^{1}$, Alexsandra Bezerra da Rocha ${ }^{2}$ \\ ${ }^{1}$ Discente da Universidade Federal de Campina Grande do curso de licenciatura em Geografia do Centro de Formação \\ de Professores - CFP/UFCG da cidade de Cajazeiras-PB. E-mail: lucianabelso@gmail.com. ORCID ID: \\ http://orcid.org/0000-0001-6433-522X. \\ ${ }^{2}$ Professora da Universidade Federal de Campina Grande, campus Cajazeiras. Doutora em Geografia - linha de \\ pesquisa Dinâmica Territorial e Ambiental - UFC - com periodo Sanduíche na Universidade de Lisboa - Portugal, Mestre \\ em Geografia - UFC. Coordenadora do Grupo de Pesquisa no CNPq Alfabetização e letramento cartográfico analise de \\ dados espaciais. Coordenadora do Laboratório de Cartografia e Geoprocessamento - LACARGEO. E-mail: \\ alexsandra.bezerra@professor.ufcg.edu.br.ORCIDID: https://orcid.org/0000-0002-4814-0999.
}

Artigo recebido em 12/01/2021 e aceito em 22/07/2021

\section{RESUMO}

Este artigo aborda sobre a aplicação didática em geotecnologias, tendo como referência conteúdos trabalhados no Ensino Médio, nas disciplinas de Geografia. Entre eles, o tema das geotecnologias que é um dos mais importantes para se correlacionar o lugar, o cotidiano e as implicações nas atividades cotidianas dos cidadãos em escala local, regional e global. O objetivo deste trabalho é apresentar uma proposta do uso de geotecnologia para o ensino médio, que possibilite a elaboração de uma carta-imagem para o estudo do lugar, suas infraestruturas. A metodologia consistiu no uso do programa Google Earth Pro (gratuito), neste alunos em formação aprenderam sobre semiologia gráfica, variáveis visuais e modos de implantação das informações (pontos, linhas ou polígonos). O uso dessa geotecnologia contribuiu para uma aprendizagem mais significativa e melhor abordagem de assuntos cartográficos e geográficos.

Palavras-chave: Ensino; Cartografia; Geotecnologia.

\section{DIDACTIC APPLICATION OF GOOGLE EARTH PRO: GRAPHIC SEMIOLOGY, VISUAL VARIABLES AND DEPLOYMENT MODES}

\begin{abstract}
This article deals with the didactic application in geotechnologies, having as reference contents worked in High School, in Geography subjects. Among them, the topic of geotechnologies, which is one of the most important to correlate place, daily life and the implications for the daily activities of citizens on a local, regional and global scale. The objective of this work is to present a proposal for the use of geotechnology for secondary education, which enables the elaboration of an image-chart for the study of the place, its infrastructures. The methodology consisted of the use of the Google Earth Pro program (free), in these undergraduate students they learned about graphic semiology, visual variables and ways of
\end{abstract}


implementing information (points, lines or polygons). The use of this geotechnology contributed to a more meaningful learning and better approach to cartographic and geographic issues.

Keywords: Teaching. Cartography. Geotechnology.

\title{
APLICACIÓN DIDÁCTICO DE GOOGLE EARTH PRO: SEMIOLOGÍA GRÁFICA, VARIABLES VISUALES Y MODOS DE IMPLANTACIÓN
}

\begin{abstract}
RESUMEN
Este artículo trata sobre la aplicación didáctica en geotecnologías, teniendo como referencia contenidos trabajad os en Bachillerato, en asignaturas de Geografía. Entre ellos, el tema de las geotecnologías, que es uno de los más importantes para correlacionar el lugar, la vida cotidiana y las implicaciones para la actividad cotidiana de los ciudadanos a escala local, regional y global. El objetivo de este trabajo es presentar una propuesta de uso de la geotecnología para la educación secundaria, que permita la elaboración de un cuadro-imagen para el estudio del lugar, sus infraestructuras. La metodología consistió en el uso del programa Google Earth Pro (gratuito), en estos estudiantes de pregrado aprendieron sobre semiología gráfica, variables visuales y formas de implementar la información (puntos, líneas o polígonos). El uso de esta geotecnología contribuyó a un aprendizaje más significativo y un mejor enfoque de los problemas cartográficos y geográficos.
\end{abstract}

Palabras clave: Enseñando. Cartografía. Geotecnología

\section{INTRODUÇÃO}

As tecnologias geográficas são ferramentas pedagógicas que proporcionam o despertar da curiosidade e a descoberta de nova metodologia em sala de aula, fazendo com que o aluno entenda, analise e seja capaz de elaborar um novo material, para ser utilizado em sala de aula durante os seminários ou durante os estágios acadêmicos, uma vez que o material produzido pode auxiliar na ministração de conteúdos programáticos não só na geografia, mas de qualquer área curricular.

Outrossim, Sousa (2018, p. 02) destaca como as tecnologias podem impactar no processo de formação discente:

As tecnologias estão cada vez mais presentes nas nossas vidas e nas escolas, muitas ferramentas tecnológicas, surgiram para facilitar a transmissão de informações e realizar comunicações, assim os professores devem buscar se adaptarem a realidade dos alunos e suas necessidades em relação à era digital, a fim tornar eficiente o processo de ensinoaprendizado, contribuindo na construção do conhecimento dos seus alunos.

Assim, este trabalho traz uma aplicação didática. Nesta oportunidade, utilizamos o programa gratuito Google Earth Pro, para elaboração de cartas imagens.

Para o auxílio ao ensino das geotecnologias nas aulas de Geografia ou Cartografia, há disponível aos professores, por exemplo, um capítulo do livro didático com um texto de apresentação e alguns conceitos, além da indicação de filmes ou documentários. Ocorre que, a partir dos materiais didáticos disponíveis nas escolas, os professores se deparam com algumas dificuldades para 
possibilitar aos seus alunos a utilização prática das ferramentas disponíveis, e isto justifica que se busquem materiais alternativos para apoiar esse aprendizado.

O objetivo deste trabalho é mostrar como o uso de geotecnologia voltada para o ensino médio, são eficientes para o estudo dos lugares e também as formas de espacializações de informações do cotidiano dos alunos.

A ideia deste artigo surgiu durante a participação como monitora da disciplina de cartografia geral, ofertada no segundo período e sendo pré-requisito para disciplinas como ensino de cartografia e geoprocessamento. Então, deste modo, as atividades de monitoria estavam pautadas na utilização de um conjunto de geotecnologias, neste texto destacaremos os resultados obtidos do uso do software Google Earth Pro.

Os métodos utilizados foram a aplicação do Google Earth Pro nas aulas de Cartografia Geral, e sobretudo fazer os alunos em formação entenderem uma maneira diferente de aplicação tanto durante seus estágios como na sua vida profissional. Os alunos utilizaram dos princípios da semiologia gráfica, variáveis visuais e modos de implantação, difundidos no estudo de mapas temáticos.

Os resultados foram obtidos por meio de cartas-imagens confeccionadas pelos discentes que usaram as ferramentas do software para destacar as infraestruturas de vários lugares e em diferentes tipos de escalas.

Este artigo teve inspiração nos trabalhos no programa "Como Fazer?” do canal público TV Escola do MEC - Ministério da Educação, destinado a professores do Ensino Médio, exibido em 15/10/2001. E na publicação ensino das Ciências na Estação Ciência da USP em São Paulo, apresentados na $7^{\mathrm{a}}$ Mostra de Material, divulgados em 2003.

\section{A CONTRIbUiÇÃo dA MONITORIA NO PROCESSO DE APRENDIZAGEM DOS DISCENTES DO CURSO DE GEOGRAFIA}

A disciplina de Cartografia Geral tem como pressuposto proporcionar aos educandos uma reflexão acerca da questão da representação geográfica através de plantas, cartas topográ ficas e mapas temáticos, em diferentes projeções. Além da utilização de tecnologias da informação para representação de fenômenos da paisagem, seja utilizando imagens aerofotogramétrica (avião ou drone) ou imagens de satélites artificiais. 
No tocante a isso, entende-se que a monitoria acadêmica possibilita auxiliar a prática docente há um maior entendimento das questões teóricas e metodológicas que norteiam a importância da Cartografia para o geógrafo e os ensinamentos no decorrer da disciplina.

Diante da importância do trabalho do monitor na disciplina de Cartografia Geral destaca Cabral, Xavier e Caetano (2018, p. 3382):

Assim, a Monitoria de Cartografia objetiva desenvolver conhecimentos cartográficos teóricopráticos que possibilitem a formação do bacharel e do licenciado em Geografia, auxiliando os alunos na discussão sobre os principais conceitos cartográficos e suas aplicabilidades e proporcionando reflexões acerca das questões que constituem a representação gráfica, os elementos técnicos, os sistemas de coordenadas etc.

Desse modo, vemos a contribuição da monitoria no auxílio aos alunos nos conteúdos da disciplina de Cartografia Geral na formação de professores, em que teremos como foco o uso do software Google Earth Pro, em que o monitor auxilia os alunos no manuseio do mesmo durante a explicação da professora, como também fica a disposição de intermediação da turma com o docente, a partir de dúvidas e sugestões acerca da aprendizagem.

Assim, a presença de um monitor durante o processo de desenvolvimento da referida disciplina contribuirá para sanar as dificuldades encontradas pelos alunos matriculados, através da discussão de diferentes textos, resolução de exercícios com o atendimento individual ou em grupo dos alunos matriculados. (PEREIRA; ROCHA, 2017, p. 865).

A disciplina de Cartografia Geral por trata-se de uma disciplina que requer uma carga de leitura muito técnica, muitos alunos apresentam dificuldades em acompanhar seu desenvolvimento, pois, embora os textos da disciplina estejam correlacionados em termos de conteúdo, cada um apresenta suas próprias particularidades, e a compreensão das particularidades de cada texto é que proporcionam o conhecimento da realidade das questões cartográficas.

\section{A IMPORTÂNCIA DO GOOGLE EARTH PRO NA SALA DE AULA}

O Google Earth Pro é uma ferramenta importante para o aprendizado em sala de aula e a partir dele pode-se trabalhar temáticas da Geografia.

Conforme Santos et al (2015) a importância da capacitação do Google Earth Pro na formação discente pode contribuir na sua atuação profissional, que se inicia no estágio supervisionado, em que esse software, tem muito a contribuir nos estudos de geografia física como o relevo, a hidrografia e 
na geografia humana colabora para o estudo do território, a localização de países e continentes, dentre outros assuntos.

Segundo Neto (2009, apud Nasser, 2016, p. 22) aborda sobre o Google Earth:

Conforme Neto (2009), o Google Earth é um aplicativo computacional desenvolvido e distribuído pela empresa americana Google, cuja função é apresentar um modelo tridimensional do globo terrestre, construído a partir de um mosaico de imagens de satélite obtidas de fontes diversas. Anteriormente conhecido como Earth Viewer, este programa foi desenvolvido pela companhia Keyhole, Inc. a qual foi adquirida pela empresa Google no ano de 2004.

A versão Pro que trabalhamos durante as aulas, antes era paga, por se tratar de uso comercial, felizmente no ano de 2015 o Google passou a disponibilizá-la de forma gratuita, em que ela mantém algumas funcionalidades do Google Earth, mas com um melhor desempenho e outras funcionalidades, como a visualização em 3D.

Ferreira e Leite (2017) enfatiza a importância de o professor conhecer as bases norteadoras do ensino, antes de familiarizar-se com as geotecnologias, para que haja um eficiente domínio do assunto e desenvolvimento de qualidade de sua metodologia em sala de aula.

Desse modo, durante a formação dos discentes em licenciatura plena em geografia, busca-se saber como associar o uso do programa com os conhecimentos geográficos que são adquiridos durante a sua formação e como o futuro professor terá uma efetivação da sua prática como docente.

Diante disso, vemos a necessidade de preparar profissionais no uso de geotecnologias, e que isso ainda está em processo de construção, corroboram, Sousa e Albuquerque (2017, p. 85):

Essa formação consiste desde os cursos de graduação, com o apoio de professores qualificados, laboratórios e materiais tecnológicos adequados para a boa formação dos graduandos até os cursos de especialização, mestrado e doutorado na área.

Assim, a disciplina de Cartografia Geral, busca inserir os seus formandos no uso de Geotecnologias, em que no estudo desses autores, apontam ainda as dificuldades durante a graduação do curso de Geografia na formação voltada para o uso das tecnologias.

Ainda com a contribuição de Sousa e Albuquerque (2017), para que haja uma boa formação dos discentes no uso das geotecnologias, é necessário que as universidades tenham uma estrutura tecnológica com equipamentos e laboratórios, profissionais especializados na área. 
Diante disso, vemos a potencialidade dessa ferramenta e das geotecnologias na formação de professores como também na contribuição de uma nova metodologia no ensino de geografia, permitindo que:

\footnotetext{
As geotecnologias possibilitam aos professores trabalhar com dados mais atualizados sobre o espaço geográfico, inclusive com o espaço próximo do aluno, uma cidade, um bairro ou mesmo um quarteirão, suprindo assim, a carência de mapas e representações espaciais que facilitam a visualização e interpretação do espaço geográfico em constante transformação. (SOUSA e DI MAIO, 2013, p.37)
}

Dessa maneira, vemos que o uso dessas tecnologias no ensino de Geografia e na formação discente contribui para que os formandos e os alunos de educação básica tenham o conhecimento de ferramentas atualizadas sobre o estudo do espaço geográfico, em que o docente aprende durante a sua formação a não se prender, apenas em mapas impressos, desatualizados ou livro didático utilizandose como recurso pedagógico, a cartografia digital, e isso, também auxilia no estudo local dos alunos e formandos com dados atualizados.

A partir disso, vemos a importância de trabalhar geotecnologias durante a formação de discentes, não somente na Cartografia, mas em outros ramos da Geografia e principalmente nas atividades práticas e estágios.

\section{METODOLOGIA}

A proposta metodológica que se aplicou para a construção das cartas-imagens foi baseada na "Metodologia Ativa" (CANIATO, 1992). O objetivo geral da Metodologia Ativa é estimular e exercitar a iniciativa em diferentes tipos de ação, orientada pelo professor no estudo de conteúdos de Ciência para alunos dos ensinos Fundamental e Médio, utilizando uma experiência brasileira, com uma visão integrada dos demais campos do conhecimento humano. objetivos específicos da Metodologia Ativa são: Introduzir e exercitar a atividade com as mãos, Ações como ler, criticar (discutir), fazer (também com as mãos), acrescentar e cooperar, e por parte do professor exercitar, ampliar e renovar sua cultura.

O uso do Google Earth Pro serviu para trabalhar temáticas relacionadas a semiologia gráfica, variáveis visuais e modos de implantação. Assim, durante a aula sobre o Google Earth Pro houve o contato com este software, em que primeiro buscou-se explorar a barra de ferramentas (Figura 01) com o uso das funções: marcadores pontos, linha e polígonos (área), e régua ( $\mathrm{km}, \mathrm{hm}, \mathrm{cm}$, etc.) com o uso os discentes aprenderam a vetorizar elementos de diferentes tamanho e espessura. 
$\mathrm{Na}$ disciplina, foi observado durante a monitoria, principalmente nas aulas no Laboratório de Cartografia e Geoprocessamento que a aplicação prática com o Google Earth Pro, necessitava o acompanhamento e o auxílio na aprendizagem do software.

Figura 1 - Barra de ferramentas

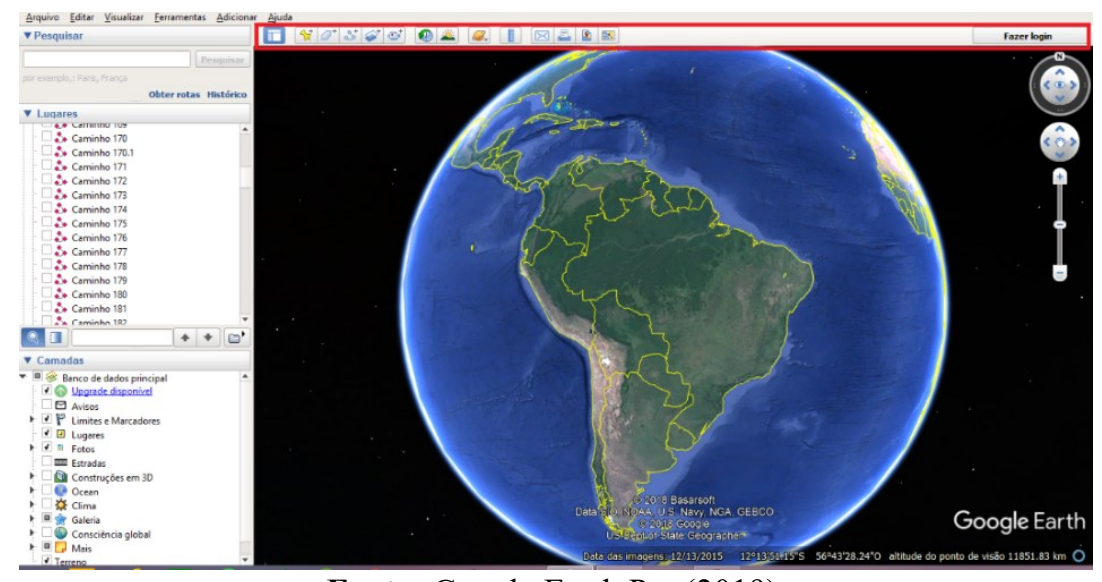

Fonte: Google Earth Pro (2019)

Durante a monitoria foi proporcionado a oportunidade de ministrar uma aula com essa ferramenta. Esta foi dividida por etapas e acompanhada pela professora. Foi preparado um passo a passo que indica-se, todas as ferramentas a serem utilizadas:

Como pode ser visto na figura 02, a barra de ferramentas está destacada por um retângulo vermelho em que tem as funções que vão ser abordadas, destacando suas funcionalidades.

Figura 2- Barra de ferramentas e as suas principais funções

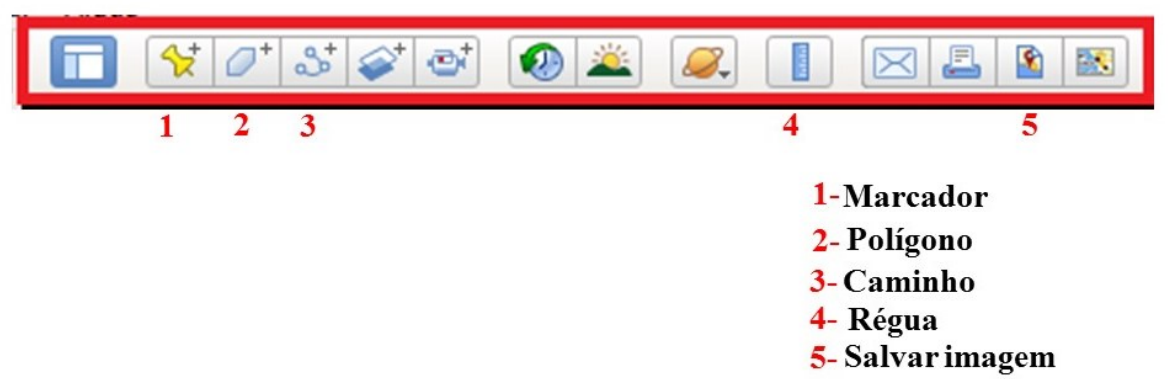

Fonte: Google Earth Pro (2019), barra de ferramentas.

As funções que foram trabalhadas em sala de aula são as que estão numeradas (figura 02), estas servem para vetorizar as imagens, criando, assim o nosso mapeamento dos elementos presentes na imagem de satélite. O ícone de número 1 tem como finalidade a criação de pontos na imagem de satélite, como por exemplo, marcar a localização da biblioteca. Também, pode-se mudar a cor ou o símbolo do ícone (Figura 03). 
Figura 3- Ícone dos marcadores

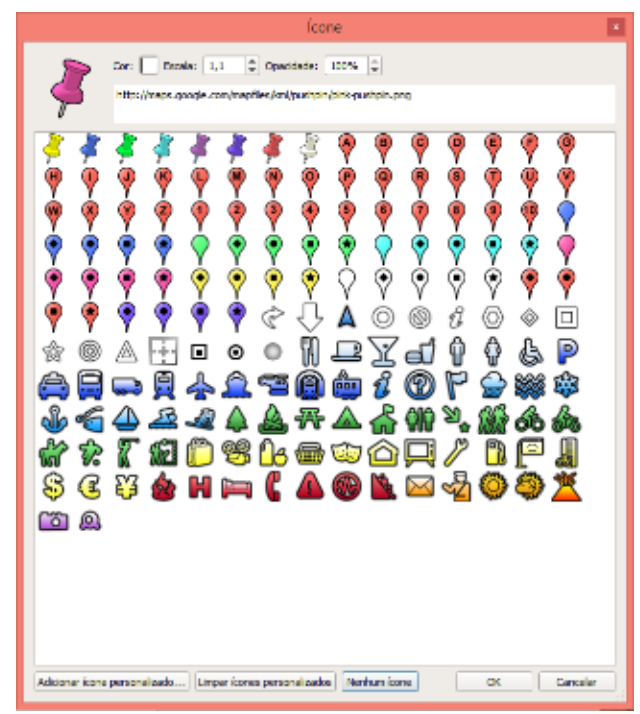

Fonte: Google Earth Pro (2019).

Ainda na figura 03, ver-se as opções símbolos para os ícones, que se pode acrescentar, como também mudar a cor. Essa variedade ajuda melhor para a legenda que podemos diferenciar os marcadores e associar com o elemento que está sendo vetorizado como o símbolo do avião, por exemplo, que indica aeroporto. No ícone 2 (figura 02), pode-se criar um polígono, ou seja, uma forma geométrica que pode ser um retângulo, triângulo, dentre outra. No ícone 3 (Figura 02), pode-se criar uma linha, em que traçamos por exemplo, uma rua, esta ferramenta indica também o comprimento da rua em vários tipos de unidades de medidas e também pode-se modificar a cor e a espessura (Figura 08).

O ícone 4 (Figura 02), trata-se de uma régua, com a mesma pode-se ativar as funções anteriores, com exceção do marcador, em que também podemos criar polígonos e caminhos em 3D realizando o mesmo processo, mas sendo utilizado as três dimensões (na matemática são as coordenadas $\mathrm{x}, \mathrm{y}$ e $\mathrm{z}$ ), em que geralmente essas imagens em 3D vão estar disponíveis principalmente em capitais (Figura 13). Esta função permite também a criação do círculo em que para fazê-lo, localizamos o centro da área e puxamos como mouse até formar o círculo. Além disso, é possível criar um perfil topográfico, como observa-se na figura 04. 
Figura 4- Perfil Topográfico

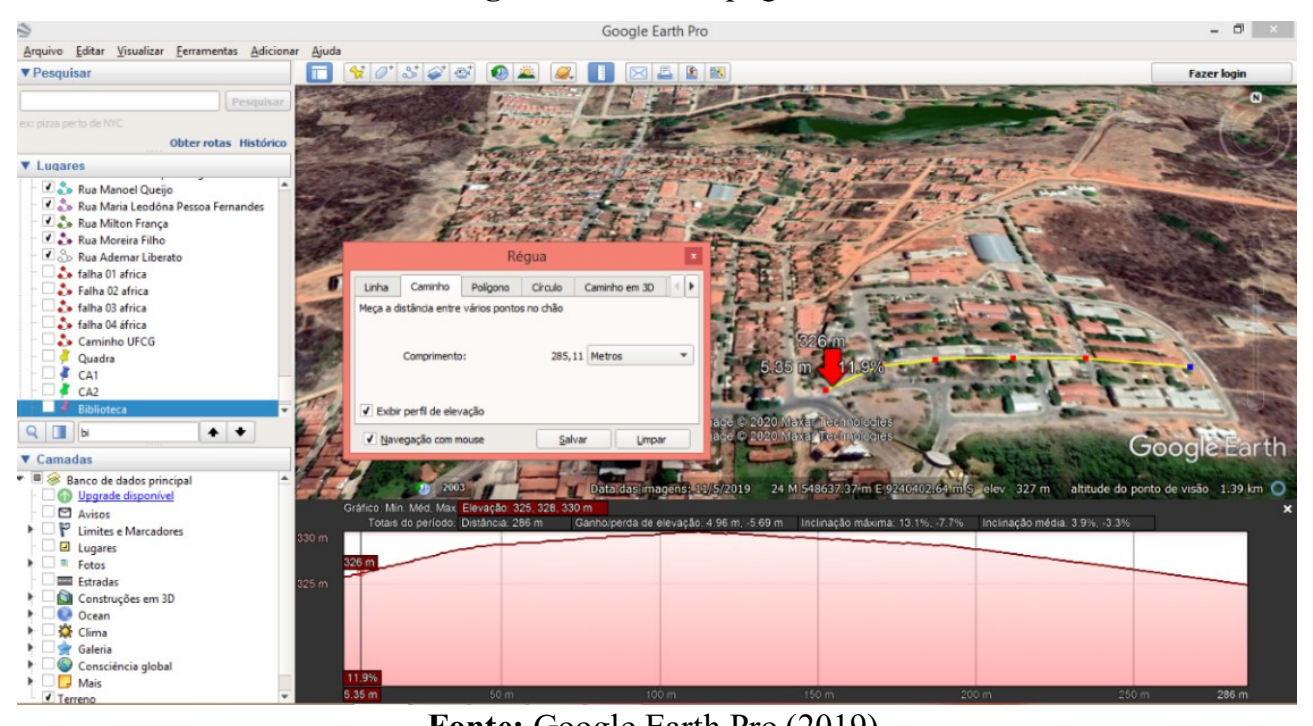

Fonte: Google Earth Pro (2019).

Na figura 04, o perfil topográfico, ver-se, as características do relevo com uma leve inclinação, com a menor altitude bem próxima do ponto mais elevado deste perfil. A seta vermelha indica o ponto da altitude e a inclinação do ponto que está sendo indicado. Também pode-se obter o perfil topográfico como mostrado na figura 10 em que clicamos como botão direito do mouse em um caminho já feito e clica-se novamente em perfil de elevação, que também teremos o mesmo resultado. Apesar do Google Earth Pro mostrar o perfil topográfico, não podemos esquecer que essa ferramenta não pode ser substituída pela topografia tradicional com o uso de teodolitos ou estações totais, em que o seu uso só é recomendado caso não tenha acesso ao local que está sendo mapeado.

O ícone 5 (Figura 02) é para salvar a imagem, quando terminamos o processo de vetorização, iremos criar a partir desta ferramenta a carta-imagem, em que quando ativamos, aparecem os principais elementos de um mapa como o título, a legenda, a descrição, o símbolo do Google Earth Pro, a escala e a orientação, como pode-se observar na figura 14 todos os elementos podem ser editados.

Para baixar esse programa deve-se acessar o site do Google Earth Pro: https://www.google.com.br/earth/download/gep/agree.html em seguida clica em concordar e fazer o download (Figura 05) e pronto o software será baixado e depois deve-se executá-lo para instalar e estará pronto para usá-lo em computador com acesso à internet. 
Figura 5- Download Google Earth Pro

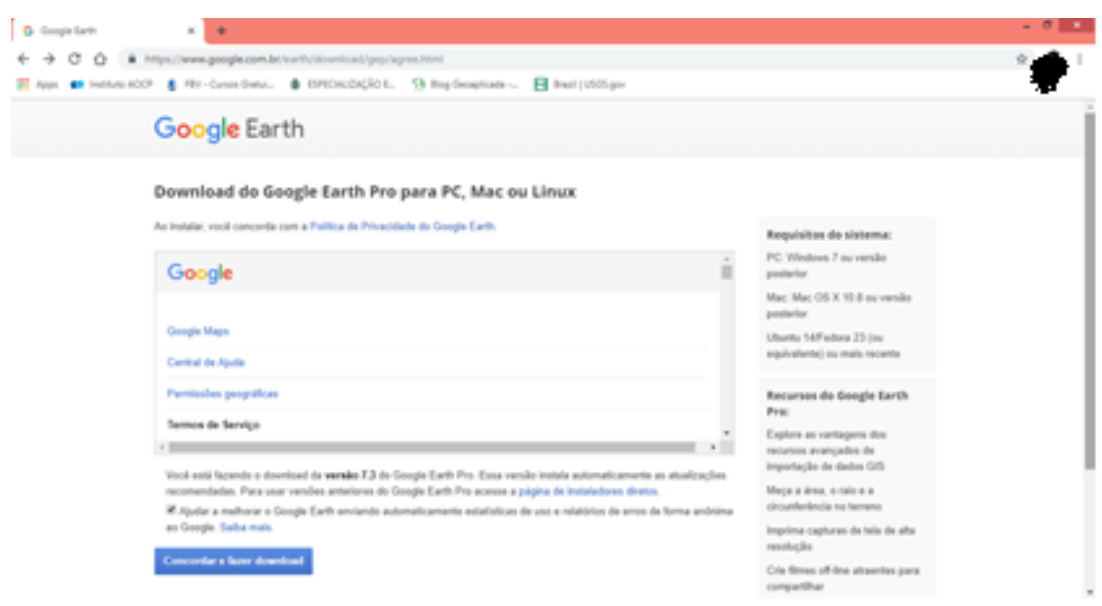

Fonte: Site do download Google Earth Pro (2019).

Conforme apresentado, essa metodologia foi desenvolvida com os discentes durante a prática de monitoria na disciplina de Cartografia Geral, que eles puderam ter um contato com o software, desde como baixa-lo até manusear as suas principais ferramentas, que como forma de aprendizado, podem desenvolver esse mesmo método durante as suas práticas nas atividades de docência.

\section{RESULTADOS}

As aulas foram ministradas para alunos em formação em licenciatura plena em geografia, no ano de 2018. O software utilizado foi o Google Earth Pro que propicia em sua aprendizagem o contato com outras áreas do conhecimento. Exemplo: régua, polígono e caminho em que ambos mostravam unidades de medidas, como área de um polígono ou quantos metros percorridos de uma rua, então, os alunos teriam que ter um domínio de alguns conceitos básicos da cartografia, a exemplo do cálculo de área e escala.

Primeiramente foi trabalhado a questão da semiologia gráfica (elementos do mapa), variáveis visuais (tamanho, cor, forma, textura, valor e granulação) e modos de implantação (pontos, linhas e polígonos), definidos nos estudos de cartografia temática.

A partir da ferramenta marcadores é possível inserir na imagem diferenciando por cor e tamanho os marcadores (Figura 06) para localização de um determinado objeto. 
Figura 6 - Marcadores

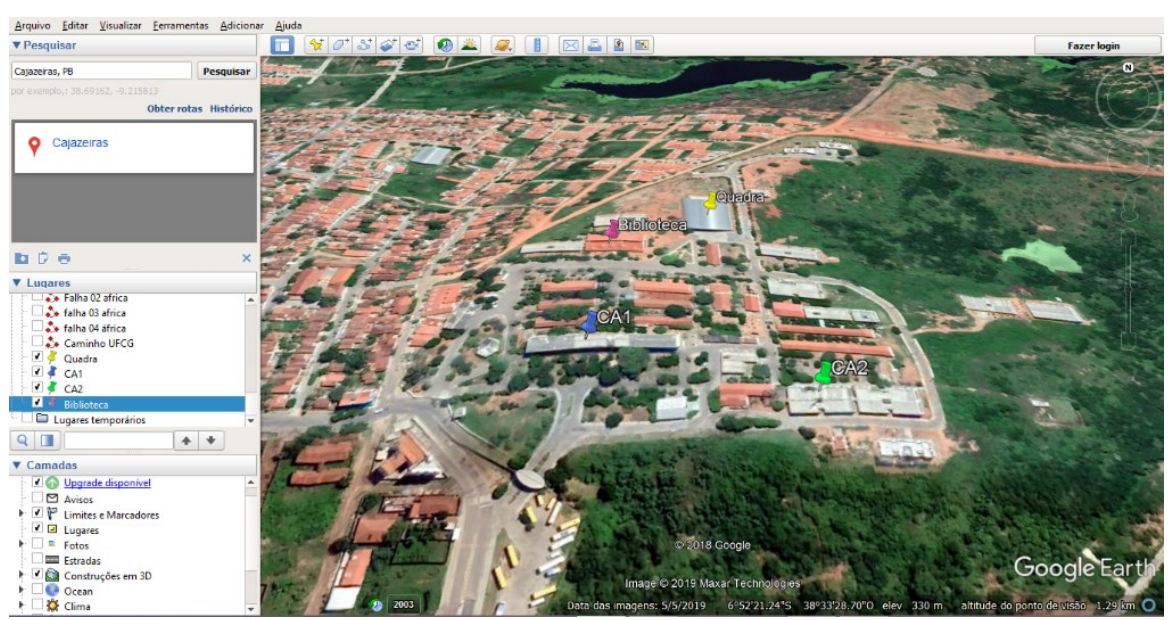

Fonte: Google Earth Pro (2019).

Percebe-se que os marcadores (Figura 06) indicam alguns locais como a biblioteca, central de aulas e quadra poliesportiva. Também tem como mudar a simbologia ou a cor dos marcadores.

Com a ferramenta polígono (Figura 07), tem como aprender a traçar uma figura geométrica podendo ser um quadrado, triângulo ou outra forma que deseja representar. Pode-se definir a cor do polígono como também visualizar a área e o perímetro do mesmo, além da transparência.

Figura 7 - Polígono

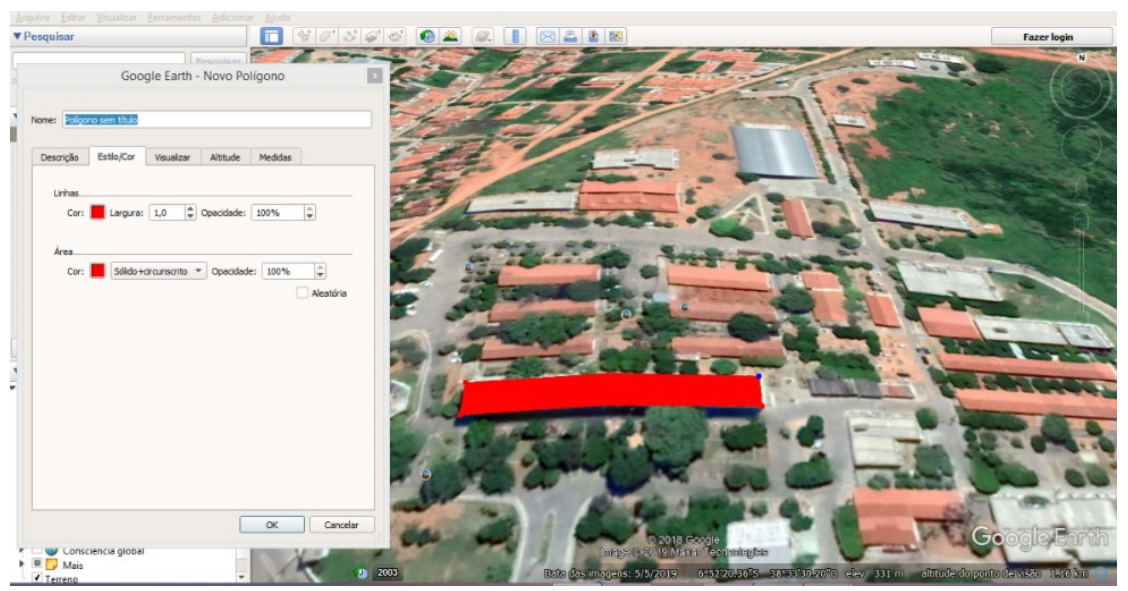

Fonte: Google Earth Pro (2019).

Observa-se um retângulo vermelho (Figura 07) feito pela ferramenta polígono em que vai marcar os vértices da área para formar um polígono, que neste caso, desenhou o ambiente de aulas. Esta ferramenta também permite a visualização das medidas em metros, quilômetros, polegadas, metros quadrados, dentre outros.

A ferramenta caminho (Figura 08) permite que realize um traço de uma rua nas unidades de medidas como metros, centímetros, quilômetros, polegadas e entre outras disponíveis no software. 
Figura 8- Caminho

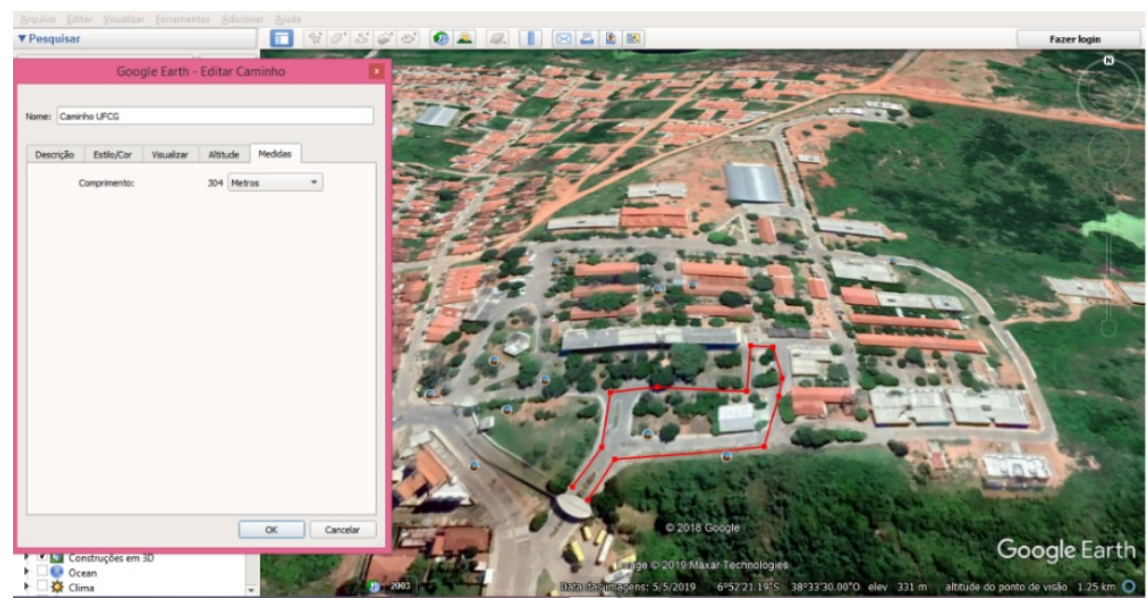

Fonte: Google Earth Pro (2019).

Vê-se um caminho traçado em vermelho (Figura 08). A ferramenta régua permite que obtemos as medidas a partir de linha, caminho, polígono, círculo, caminho em 3D e polígono em 3D.

Figura 9 - Régua (linha)

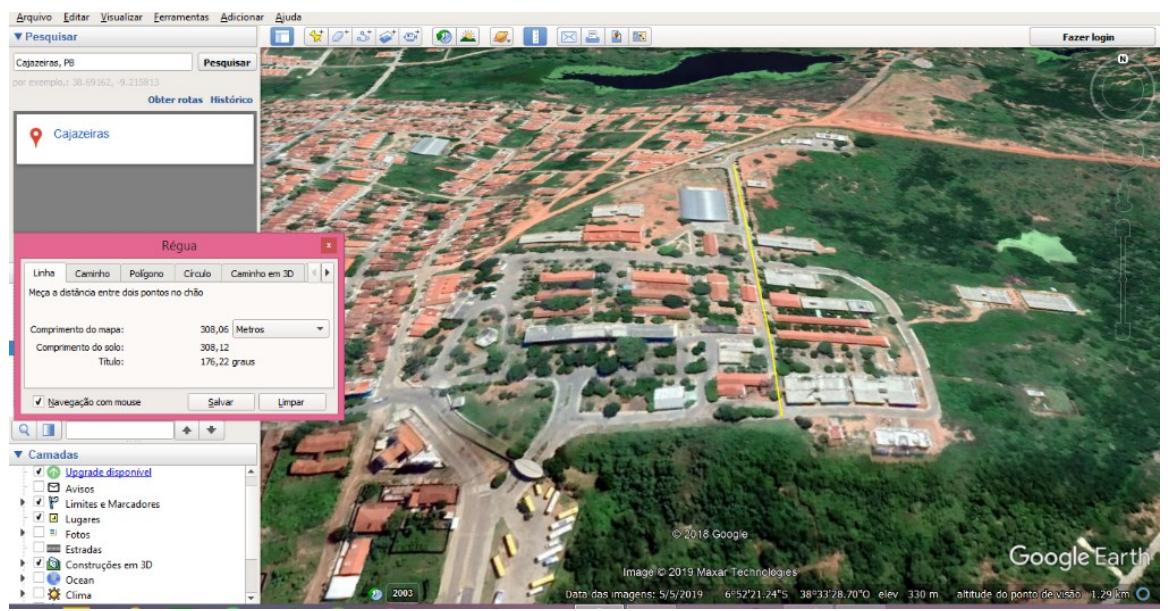

Fonte: Google Earth Pro (2019).

Nesta figura 09, observa-se o traço feito utilizando a ferramenta régua com a função linha para obter o comprimento de uma rua. Com esse mesmo caminho podemos medir a elevação a partir de perfil topográfico (Figura 10). 
Figura 10 - Perfil Topográfico a partir da ferramenta caminho.

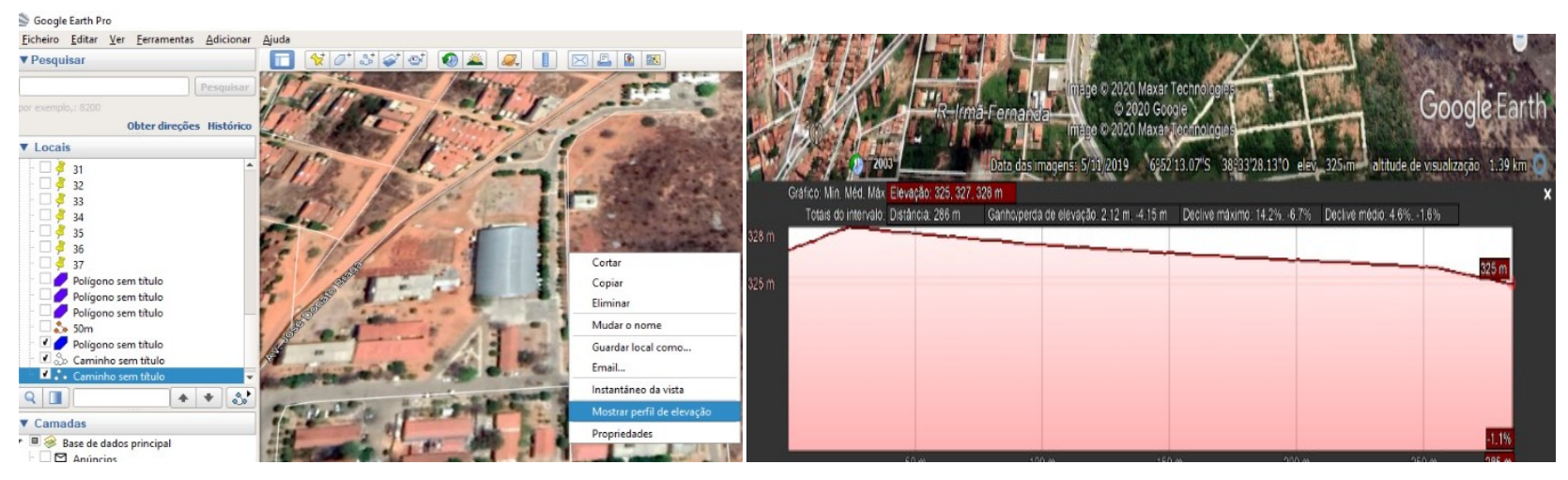

Fonte: Google Earth Pro (2019).

Outras questões podem ser feitas como a função polígono em que obteremos a medida do caminho traçado de acordo com as unidades de medidas disponíveis no software (Figura 11).

Figura 11 - Régua (polígono)

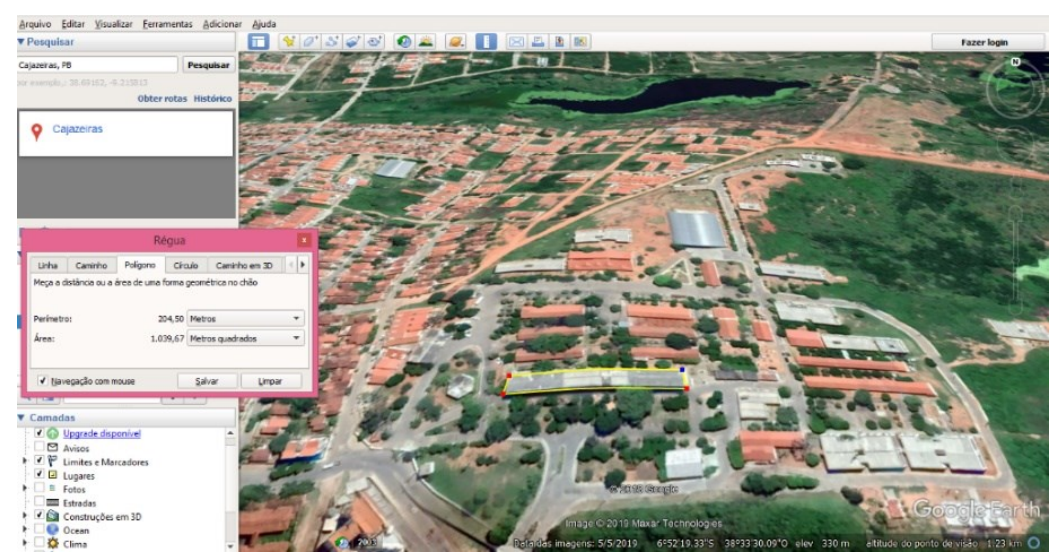

Fonte: Google Earth Pro (2019).

Vê-se nesta figura 11 o uso da régua como polígono para obter as medidas da central de aulas, em que os valores estão em metros e metros quadrados, podendo ser também usados outros tipos de medidas como em hectares. 
Figura 12 - Régua (círculo)

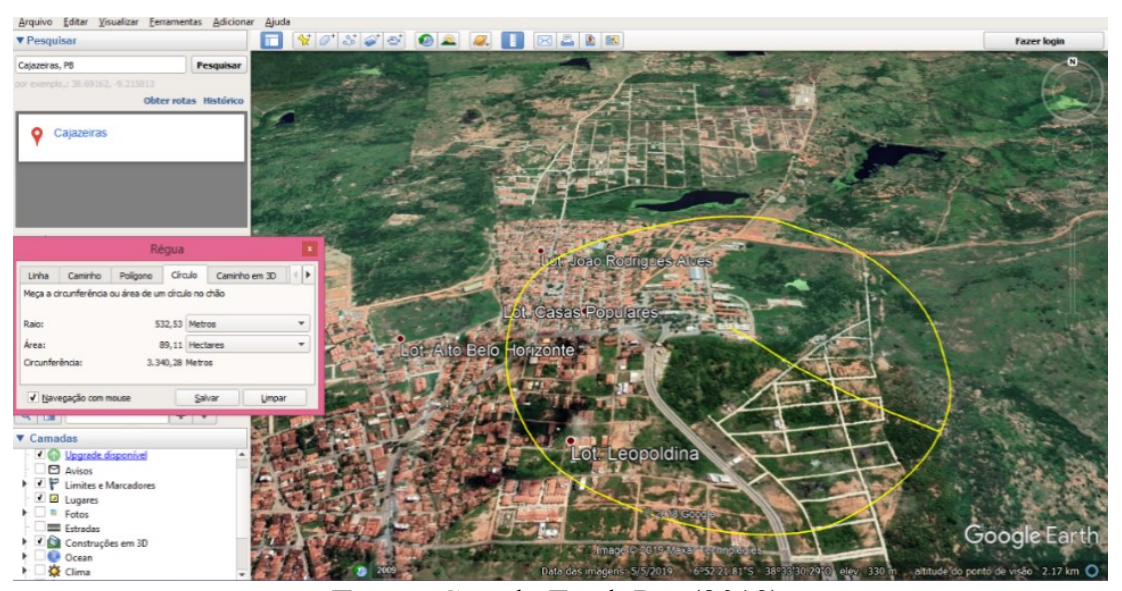

Fonte: Google Earth Pro (2019).

O círculo (Figura 12) pode ser usado para obter a medida de uma área circular ou calcular uma área de influência, que neste caso temos como representação de uma determinada área, com o seu raio de influência. Pode-se obter a medida do raio, a área do círculo e a circunferência que é dada somente em metros.

Nesta função da régua (Figura 13) podemos fazer um polígono em três dimensões, em cidades que apresentam as construções em 3D, como é o caso representado na imagem de um prédio em João Pessoa-PB, com o polígono feito somente de um lado do prédio, podendo ser estendido nas demais dimensões do mesmo. Pode-se obter as medidas do perímetro e a área do polígono em 3D.

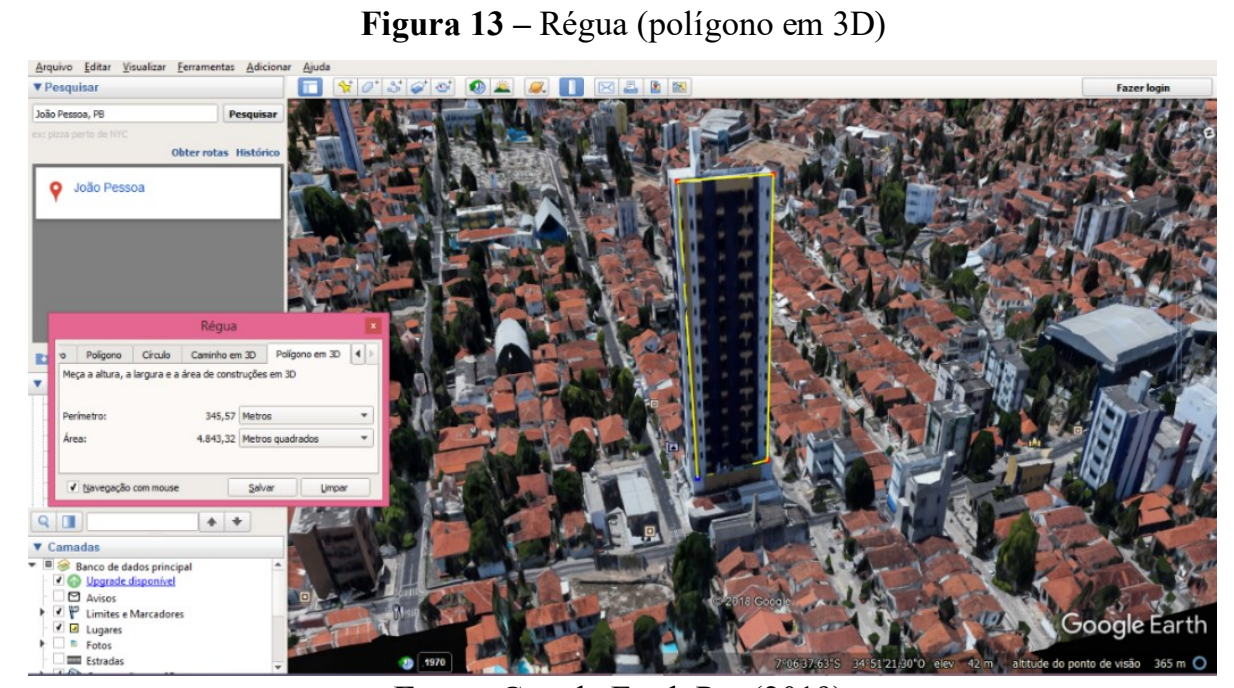

Fonte: Google Earth Pro (2019).

A partir do conhecimento das funcionalidades da barra de ferramentas pode-se ir para o próximo passo que é a confecção das cartas-imagem. Com o uso dessas funções cria-se vetores e 
destacando lugares que são necessários para a confecção (Figura 14). Nela estará contida os principais elementos de um mapa que são título, legenda, orientação e escala e data da imagem.

A partir do que foi exposto, tivemos como resultado as confecções das seguintes cartasimagem pelos discentes de Geografia.

Figura 14 - Carta-imagem da localização das escolas públicas da cidade da cidade de Aurora-CE

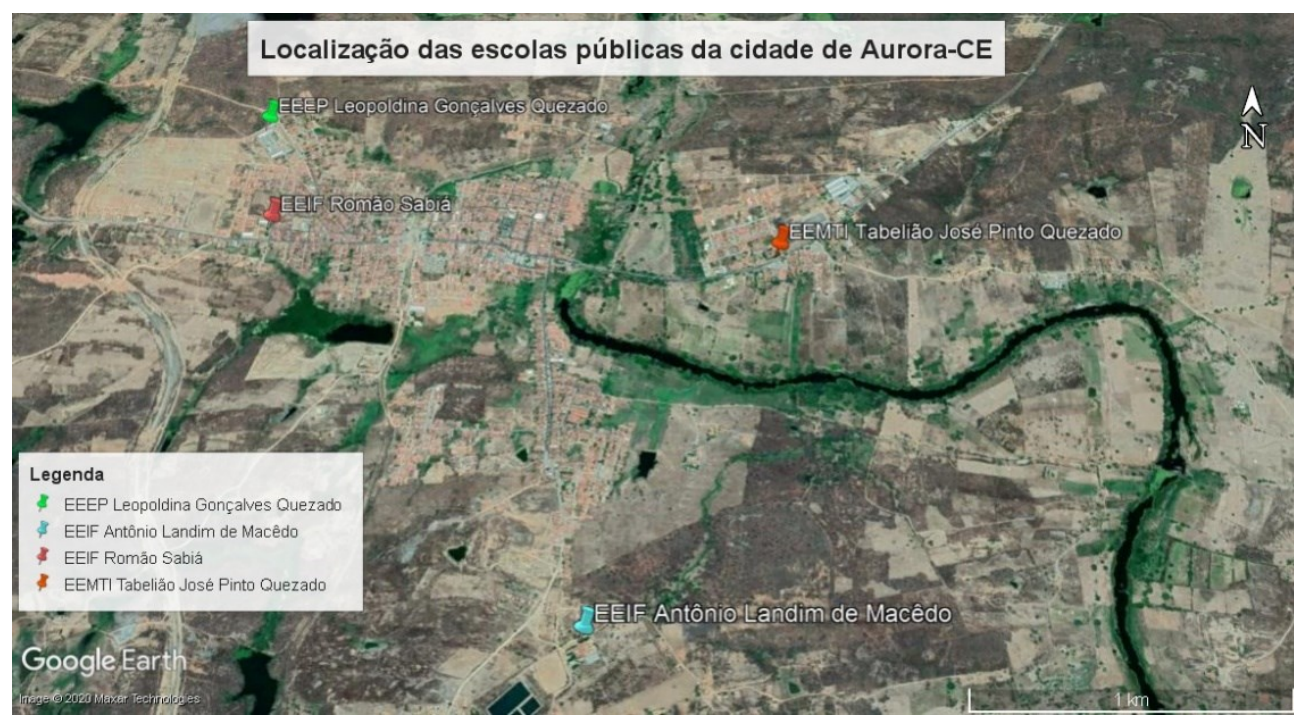

Fonte: Elaboração dos alunos (2019).

Na carta-imagem (Figura 14) está representada a localização das escolas públicas da cidade de Aurora-CE que está também sendo destacado pela legenda em que temos como elementos também o título que está no canto superior esquerdo, a orientação no canto superior direito, a escala no canto inferior direito e a logo do Google Earth Pro no canto inferior esquerdo. Esses elementos da carta imagem pode ser movidos para outro local na imagem e também são todos editáveis que com um clique, pode-se editar a legenda e o título. No caso da escala e a orientação são dadas automaticamente. Para salvar a imagem e adicionar todos os estes elementos é só clicar em salvar imagem na barra de ferramentas que edita, cria e salva a carta-imagem, havendo, portanto, uma representação do espaço mapeada, obtida através de imagem de satélite. 
Figura 15 - Carta-imagem da infraestrutura de uma instituição de ensino

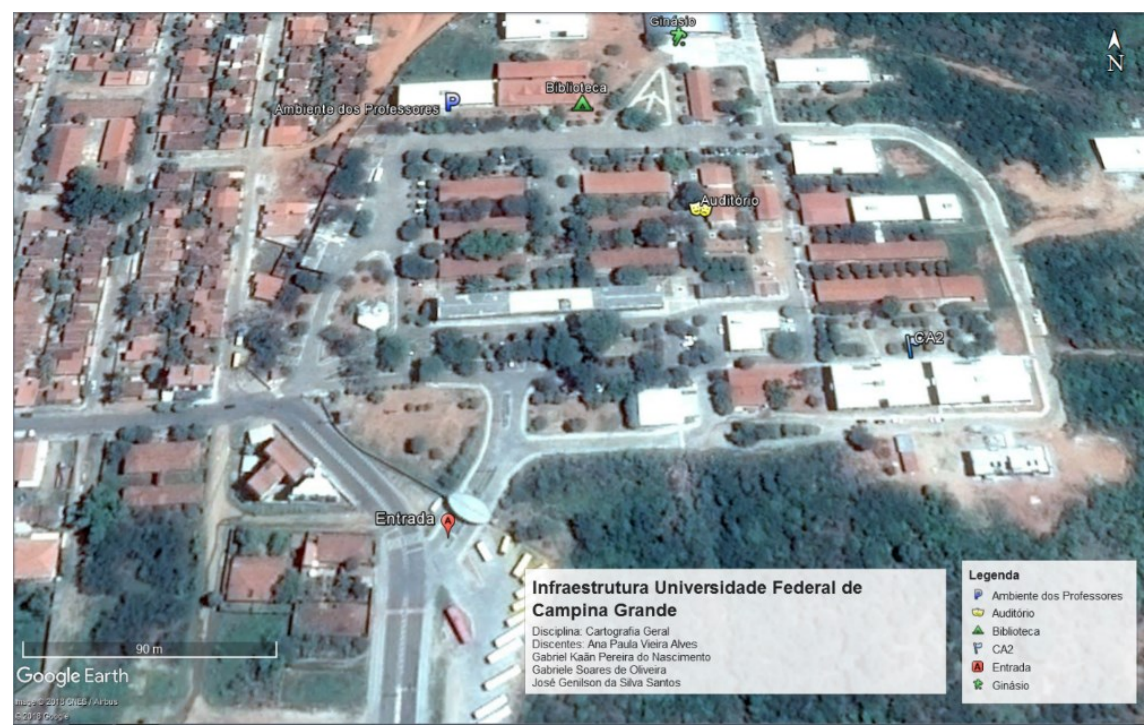

Fonte: Elaboração dos alunos (2019).

Nesta carta-imagem 15 é utilizado o marcador para localizar alguns locais, como a letra $\mathrm{P}$ indica o ambiente dos professores, o ginásio com o jogador de futebol, a biblioteca com um triângulo, o auditório pela máscara de teatro, a central de aula com uma bandeira e a entrada com um ponto com a letra A.

Figura 16 - Carta-imagem da delimitação de área rural

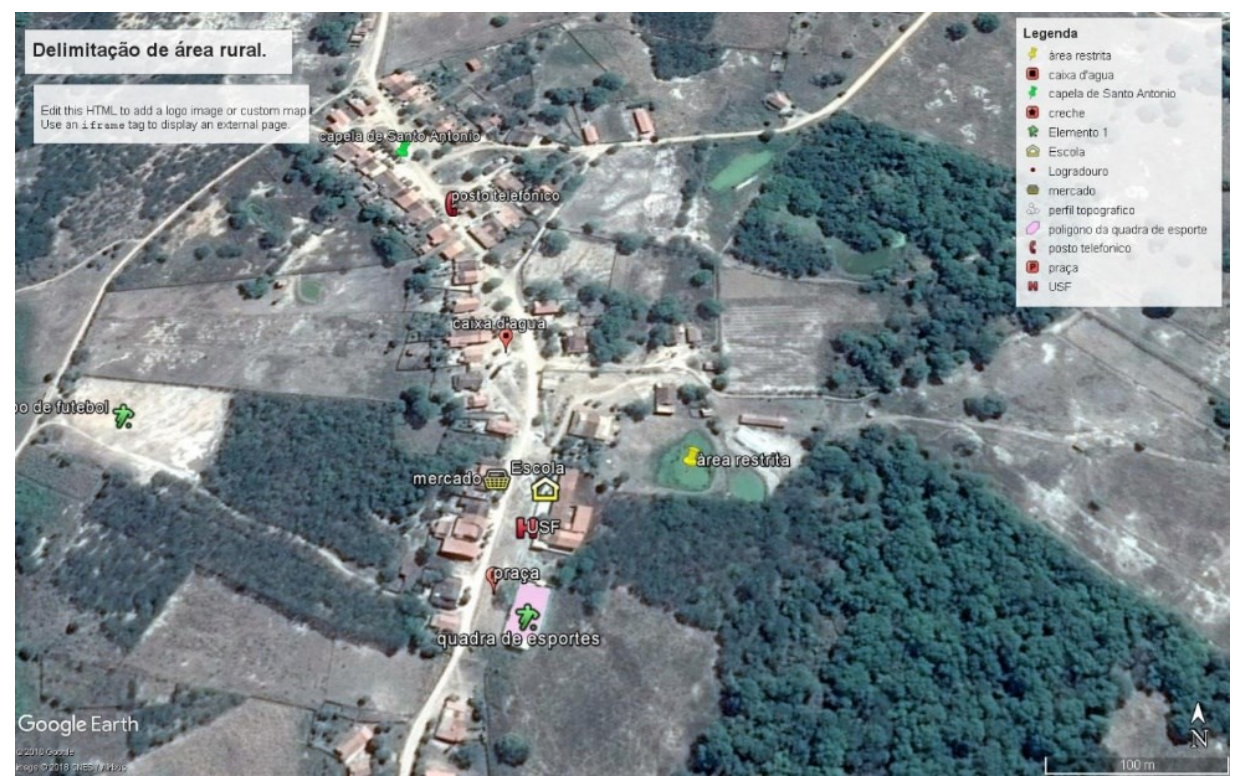

Fonte: Elaboração dos alunos (2019).

Nesta carta-imagem 16 utiliza-se o marcador para localizar alguns pontos de uma determinada zona rural como pode ser observado usa-se o telefone para indicar o posto telefônico, o mercado com uma cesta, escola com uma casinha, a praça com um ponto com a letra $\mathrm{P}$, com a letra $\mathrm{H}$ é representado 
uma USF que indica a área da saúde, área restrita com um ponto amarelo, a caixa d'água com um marcador vermelho com um quadrado, a capela de Santo Agostinho com o marcador verde, o campo de futebol e a quadra de esportes com o jogador de futebol e o polígono da quadra com a cor rosa.

Figura 17- Carta-imagem de Tenente Ananais-RN e suas infraestruturas urbanas

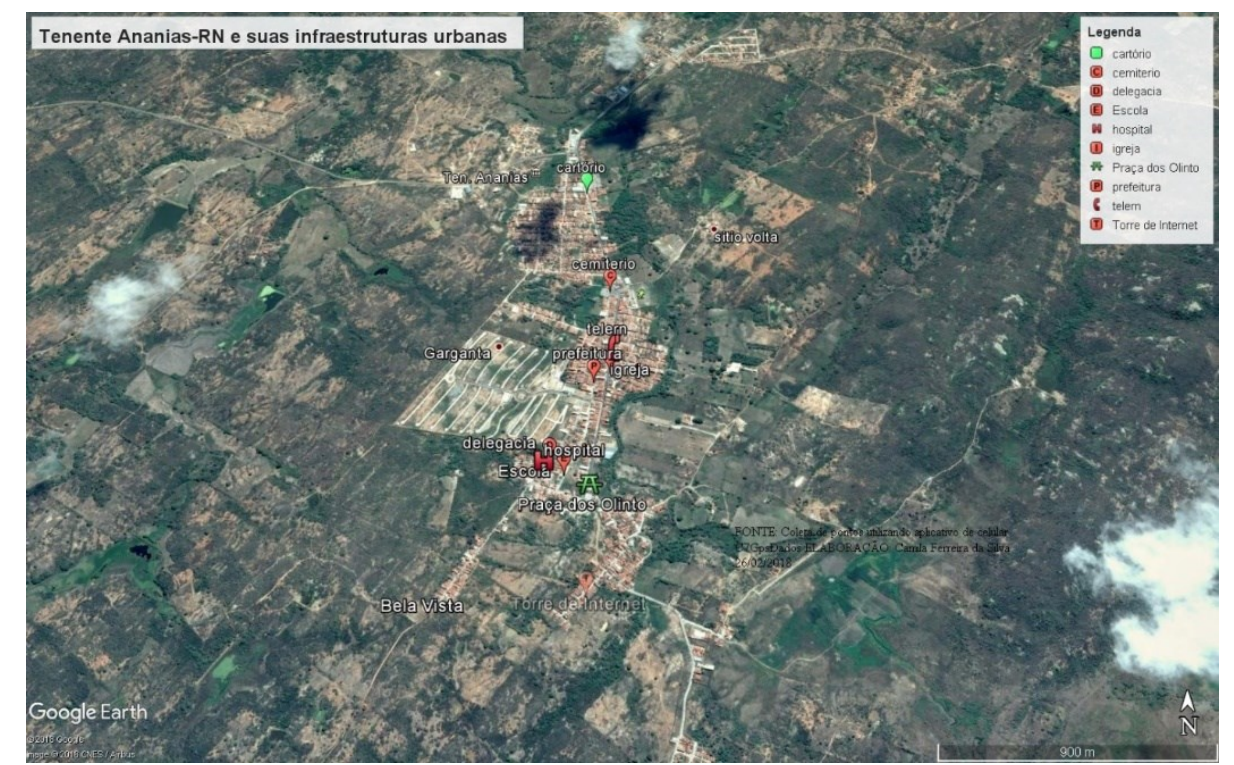

Fonte: Elaboração dos alunos (2019).

Observa-se o uso do marcador para destacar as infraestruturas presentes em Tenente AnaniasRN (figura 17) ponto verde para o cartório, a utilização de pontos com letras para indicar as iniciais das áreas marcadas como o cemitério, delegacia, escola, igreja, prefeitura e a torre de internet, telefone para indicar a telern, a letra $\mathrm{H}$ foi usada para indicar o hospital e a praça de Olinto com um símbolo diferente dos demais.

Observa-se nesta carta-imagem (Figura 18) o uso do polígono para a determinar o perímetro da área de estudo que está representado pela cor branca com aplicação da transparência de uma área de preservação permanente (APP) do município de Lavras da Mangabeira-CE, percebe-se que é um material melhor elaborado, com legenda, símbolos, descrições e layout. 
Figura 18 - Carta-imagem de uso e ocupação do solo no município de Lavras da Mangabeira-CE

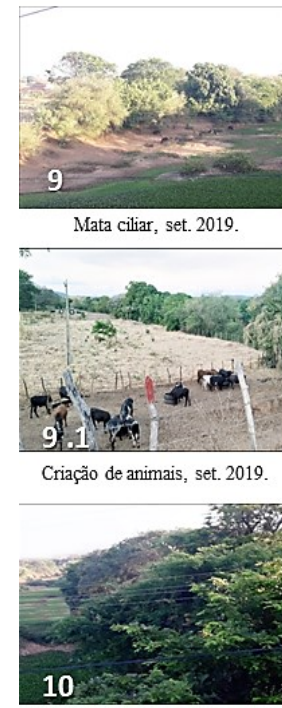

Mata ciliar, set. 2019

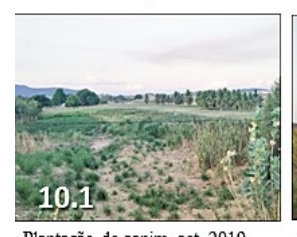

Plantação de capim, set. 2019

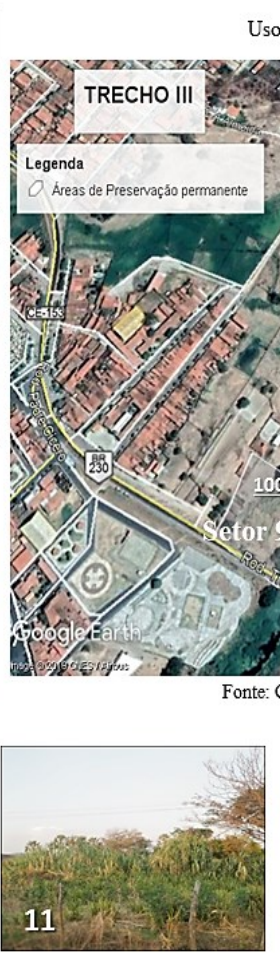

Plantação de capim, nov. 2019
Uso e ocupação do solo no trecho III

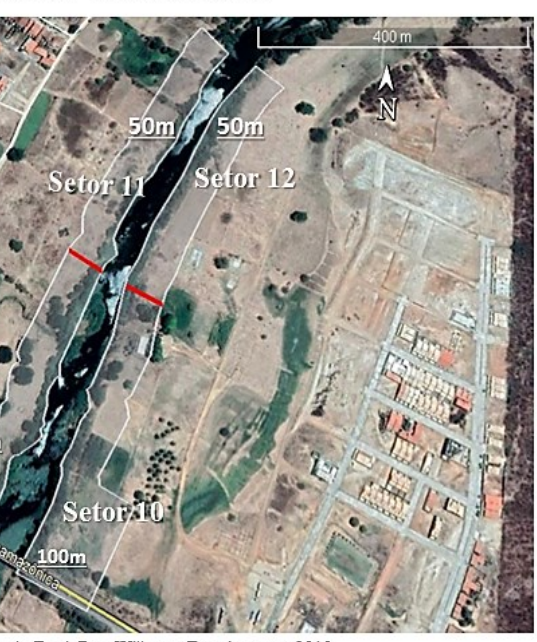

e: Google Earth Pro, Willyane Ferreira, nov. 2019.
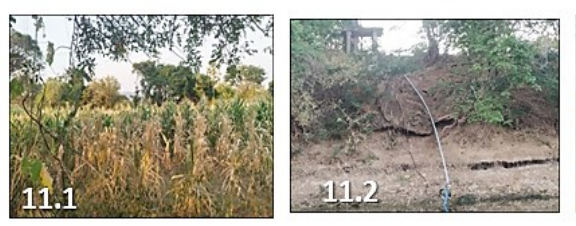

Plantação de milho, nov. 2019. Bomba para retirada de água, nov. 2019 Cercado para animais, nov. 2019

Fonte: Elaboração dos alunos (2019).

Portanto, a partir das cartas imagem confeccionadas pelos discentes, observa-se que nas duas cartas sobre a infraestrutura, os alunos apresentaram as mesmas estruturas usando símbolos diferentes. Nas demais cartas vemos representações de áreas diferentes que vimos o uso não somente de marcadores para indicar pontos, mas também de polígono e linha (caminho) como pode ser observado na carta imagem da delimitação de áreas de preservação permanentes de um rio urbano do município de Lavras da Mangabeira.

A partir do exposto, observa-se que teve-se um resultado satisfatório, os discentes que conseguiram vetorizar as infraestruturas a partir do uso de pontos, linhas e polígonos disponíveis nas ferramentas do Google Earth Pro, desse modo atende a proposta dessa atividade de confeccionar a carta-imagem a partir dos recursos disponibilizados por esse software. 


\section{CONCLUSÃO}

A monitoria contribuiu para conhecer a realidade da formação discente dos futuros professores de Geografia a respeito da Cartografia Geral e do uso de geotecnologias, e como trabalhar metodologias ativas em sala de aula, percebe-se que o processo de aprendizagem com o Google Earth Pro e o contato com esta ferramenta proporcionou um conhecimento cartográfico, mais específico.

Destaca-se a relevância do uso das geotecnologias, em que neste caso, aborda-se o Google Earth Pro na formação dos discentes em Geografia, uma vez que pode contribuir durante sua atuação profissional para uma melhor abordagem de assuntos cartográficos e também geográficos na formação de cidadãos críticos e conhecedores de sua realidade através desta metodologia.

A aplicação de trabalhos manuais para a confecção e o uso do material aqui exposto é um caminho mais concreto para se trilhar. Compreende-se também a relevância da monitoria na formação docente, pois ela é um dos primeiros contatos com a prática docente, em que se aprende na prática o que é sala de aula, uma vez que o monitor aprende as práticas e os conteúdos, oportunidade de conhecer a atividade docente mais de perto, auxiliando nas atividades práticas e na seleção de material didático e o acesso ao uso do laboratório.

\section{REFERÊNCIAS}

CABRAL, J. M. T.; XAVIER, T. W. F.; CAETANO, A. G. N. O Papel da Monitoria de Cartografia na Formação do Bacharel e Licenciado em Geografia. In: XXVII ENCONTRO DE INICIAÇÃO À DOCÊNCIA, 2018, Fortaleza. Revista Encontros Universitário da UFC, v. 3. p. 3382, 2018. Disponível em: http://periodicos.ufc.br/eu/article/view/36576. Acesso: 14 dez. 2019.

CANIATO, R. Com ciência na educação: ideário e prática de uma alternativa brasileira para o ensino da ciência. ed.3. Campinas: Papirus, 1992. p.127.

FERREIRA, W. S; LEITE, M. E. Tecnologias geográficas no ensino médio: estudo de caso em escolas públicas de Monte Claros/MG. Revista Cerrados, v.15, n.1, p. 330-350, jan/jun-2017. Disponível em: https://doi.org/10.22238/rc24482692v15n12017p330a350. Acesso: 15 dez. 2019.

NASSER, M. COMPARAÇÃO DE POLIGONAIS OBTIDAS POR GOOGLE EARTH PRO E RECEPTOR GNSS DE NAVEGAÇÃO. Trabalho de Conclusão de Curso (Graduação em Geografia) - Universidade Estadual de Londrina, Londrina, 2016. Disponível em: http://www.uel.br/cce/geo/portal/pages/arquivos/tcc_2011_2015/72_comparacaodepoligonaisobtida sporgoogleearthproereceptorgnssdenavegacao.pdf. Acesso: 10 dez. 2019.

PEREIRA, E. H. R; ROCHA, A. B. da. O PAPEL DA MONITORIA EM CARTOGRAFIA NA FORMAÇÃO DISCENTE. Revista de Pesquisa Interdisciplinar, Cajazeiras, n. 2, suplementar, p. 
864-869, set. de 2017. Disponível em: http://dx.doi.org/10.24219/rpi.v2i2.0.416. Acesso: 08 dez. 2019.

SANTOS, N. F. dos; NEUMANN, C. M; GIACOMET; A. S.C; HAURESKO, C. O uso das geotecnologias no ensino da geografia. In: XII CONGRESSO NACIONAL DE EDUCAÇÃO, 2015, Curitiba. Anais [...]. Curitiba: PUC-PR, 2015, p. 9946-9957. Disponível em: https://educere.bruc.com.br/arquivo/pdf2015/18979_10710.pdf. Acesso em: 28 dez. 2019.

SOUSA, I. B., DI MAIO, A. C. GEOTECNOLOGIAS NO ENSINO BÁSICO: UM ESTUDO DE CASO JUNTO AOS PROFESSORES DA REDE PÚBLICA DE ENSINO DO RIO DE JANEIRO. Revista Tamoios, São Gonçalo-RJ, ano 08, n. 2, págs. 29-39, jul/dez. 2012. Disponível em: https://doi.org/10.12957/tamoios.2012.4507. Acesso: 22 dez. 2019.

SOUSA, J. J. O uso do Google Earth no ensino de geografia: uma experiência na escola municipal mariano borges leal. In: CONGRESSO INTERNACIONAL DE EDUCAÇÃO E TECNOLOGIAS E ENCONTRO DE PESQUISADORES EM EDUCAÇÃO A DISTÂNCIA, 2018, São Carlos p. 0115. Anais [...]. São Carlos: Ufscar, 2018. Disponível em: https://cietenped.ufscar.br/submissao/index.php/2018/article/view/42. Acesso em: 20 dez. 2019. 